\title{
Cerebral Arterial Calcification Is an Imaging Prognostic Marker for Revascularization Treatment of Acute Middle Cerebral Arterial Occlusion
}

\author{
Seong-Joon Lee, ${ }^{\mathrm{a}}$ Ji Man Hong, ${ }^{\mathrm{a}}$ Manyong Lee, ${ }^{\mathrm{a}}$ Kyoon Huh, ${ }^{\mathrm{a}}$ Jin Wook Choi, ${ }^{\mathrm{b}}$ Jin Soo Lee ${ }^{\mathrm{a}}$ \\ Departments of ${ }^{\mathrm{a}}$ Neurology and ${ }^{\mathrm{b}}$ Radiology, Ajou University School of Medicine, Ajou University Medical Center, Suwon, Korea
}

Background and Purpose To study the significance of intracranial artery calcification as a prognostic marker for acute ischemic stroke patients undergoing revascularization treatment after middle cerebral artery (MCA) trunk occlusion.

Methods Patients with acute MCA trunk occlusion, who underwent intravenous and/or intra-arterial revascularization treatment, were enrolled. Intracranial artery calcification scores were calculated by counting calcified intracranial arteries among major seven arteries on computed tomographic angiography. Patients were divided into high ( $\mathrm{HCB} ;$ score $\geq 3$ ) or low calcification burden $(\mathrm{LCB} ;$ score $<3)$ groups. Demographic, imaging, and outcome data were compared, and whether HCB is a prognostic factor was evaluated. Grave prognosis was defined as modified Rankin Scale 5-6 for this study.

Results Of 80 enrolled patients, the HCB group comprised 15 patients, who were older, and more commonly had diabetes than patients in the LCB group. Initial National Institutes of Health Stroke Scale (NIHSS) scores did not differ (HCB 13.3 \pm 2.7 vs. LCB 14.6 \pm 3.8 ) between groups. The final good reperfusion after revascularization treatment (thrombolysis in cerebral infarction score 2b-3, HCB 66.7\% vs. LCB 69.2\%) was similarly achieved in both groups. However, the HCB group had significantly higher NIHSS scores at discharge (16.0 \pm 12.3 vs. $7.9 \pm 8.3$ ), and more frequent grave outcome at 3 months (57.1\% vs. $22.0 \%$ ) than the LCB group. HCB was proven as an independent predictor for grave outcome at 3 months when several confounding factors were adjusted (odds ratio 4.135, 95\% confidence interval, 1.04516.359, $P=0.043$ ).

Conclusions Intracranial HCB was associated with grave prognosis in patients who have undergone revascularization for acute MCA trunk occlusion.

Keywords Vascular calcification; Middle cerebral artery infarction; Intracranial embolism; Intracranial thrombosis; Thrombolytic therapy; Risk factors

\author{
Correspondence: Jin Soo Lee \\ Department of Neurology, Ajou \\ University School of Medicine, \\ 164 Worldcup-ro, Yeongtong-gu \\ Suwon 443-380, Korea \\ Tel: $+82-31-219-5175$ \\ Fax: +82-31-219-5178 \\ E-mail: jinsoo22@gmail.com
}

Received: October 8, 2014 Revised: December 15, 2014 Accepted: December 18, 2014

This work was supported by the new faculty research fund of the Ajou University School of Medicine.

The authors have no financial conflicts of interest.

\section{Introduction}

Intracranial calcified arteries are encountered in approximately $85 \%$ of patients with acute ischemic stroke. ${ }^{1}$ Intra-arterial calcification is usually accompanied by coronary atherosclerosis, and is frequently observed in the intracranial arteries. ${ }^{2,3}$ Recent studies have indicated that intracranial arterial calcification (IAC) is associated with a poor outcome in acute ischemic stroke. ${ }^{4,5}$ In the case of coronary disease, high coronary artery calcification scores can predict future ischemic coronary syndromes. ${ }^{6}$ In patients with acute coronary syndromes that received urgent intervention, moderate to severe calcification was significantly associ- 
ated with higher mortality rates 1 year after the intervention. ${ }^{7}$

The higher mortality rates are thought to be associated with complexity of coronary interventions, procedure related complications, and major adverse cardiac events such as target lesion revascularization, and non-target lesion revascularization. ${ }^{8,9}$

The significance of IAC in ischemic stroke, however, has not yet been determined. Additionally, the clinical significance of IAC in acute stroke patients who had cerebral arterial occlusion and received revascularization treatment remains unclear, for previous studies had only concluded that associations between cerebral artery calcification and mortality or poor functional outcome in the first year after ischemic stroke are mainly age and stroke severity driven. ${ }^{5}$

Revascularization after acute ischemic stroke is a developing therapy. ${ }^{10}$ Intravenous (IV) recombinant tissue plasminogen activator (rtPA) was the first agent approved for treating acute ischemic stroke. ${ }^{11}$ Recently, intra-arterial (IA) revascularization therapies, including fibrinolysis and mechanical thrombectomy, ${ }^{12-20}$ have been used on the grounds that early recanalization guarantees a better prognosis. ${ }^{21}$ However, approximately $40 \%$ of these patients fail to show neurological recovery, even with successful revascularization. ${ }^{22,23}$ Therefore, a reliable predictor for successful revascularization therapy would be clinically valuable.

The aim of the present study was to examine the clinical significance of a high IAC burden, and to clarify the factors that are associated with calcification burdens that may influence the outcomes in these patients. To achieve this goal, we used computerized tomography (CT) angiography in patients with acute middle cerebral artery (MCA) trunk occlusion who underwent hyperacute revascularization therapy.

\section{Methods}

\section{Study population}

We performed a retrospective study based on consecutive patients enrolled to a hospital stroke database that was approved by the Institutional Review Board and performed in accordance with the ethical standards of the 1964 Declaration of Helsinki and its later amendments. We registered in our thrombolysis database 361 patients with acute ischemic stroke who underwent revascularization therapy between January 2006 and September 2011. From these 361 patients, we selected patients who met the following inclusion criteria: (1) acute stroke due to an occlusion in the main trunk of the MCA identified on initial CT angiography performed within $6 \mathrm{~h}$ of onset, (2) National Institutes of Health Stroke Scale (NIHSS) score $\geq 5$, (3) IV and/or IA treatment, and (4) transfemoral cerebral angiography performed during the hyperacute period. The first and fourth criteria were included to evaluate leptomeningeal collaterals and final reperfusion status, respectively. If a frank hypodensity was seen in more than one third of MCA territory, the patient did not undertake IA treatment.

\section{Protocols}

CT scans (including non-enhanced [NECT], postcontrast axial parenchymal images, and CT angiography; SOMATOM Sensation 16, Siemens, Erlangen, Germany) were obtained for each patient after they were admitted to the emergency department. Noncontrast and postcontrast CT scans were performed by use of the axial technique with $120 \mathrm{kVp}, 270 \mathrm{~mA}$, and 5-mm section thickness reconstructions. CTA was performed by scanning from the vertex to aortic arch by use of the following parameters: $0.5 \mathrm{~s} /$ rotation, pitch, 1.3; collimation, $0.75 \mathrm{~mm}$; maximal $\mathrm{mA}$, 170 ; $\mathrm{kVp}, 100$; field of view, $22 \mathrm{~cm}$. Nonionic contrast material (80-100 mL) was administered by power injector at $4-5 \mathrm{~mL} / \mathrm{s}$ into an antecubital vein with a semi-automatic contrast bolus triggering technique. The CTA source images were postprocessed to create coronal, sagittal, and axial multiplanar reformats in maximum intensity projection (MIP) images and volume rendered 3D images. IV rtPA was administered as soon as the infusion could be started, which typically was within 3 hours of symptom onset. Patients without contraindications for endovascular treatment were sent to the angiographic suite. If the initial angiography showed occlusion, they were treated immediately using the IA approach when the onset-to-groin puncture interval was expected to be less than 6 hours, irrespective of IV rtPA infusion. Endovascular revascularization treatment started based on transfemoral cerebral angiography (Allura Xper FD20/10, Philips Healthcare, Best, the Netherlands). The endovascular treatment methods were determined by interventionists' discretion.

NECT was performed after the endovascular procedure. Magnetic resonance imaging (MRI; Achieva, Philips Healthcare, Best, the Netherlands), including diffusion-weighted imaging, was performed within 2 days of symptom onset for patients enrolled in the study before January 1, 2010, but was performed after IV rtPA infusion and before IA procedures for patients enrolled after this date. NECT, CT angiography, and MRI were repeated for all patients within 7 days of revascularization therapy. Neurological scores, including the NIHSS and the modified Rankin Scale (mRS), were determined daily until discharge, and then mRS was rated at the 3rd month following their discharge. If the patient could not come to the clinic, mRS was measured by phone interviews. Well-trained nurses determined the neurological scores in outpatient clinics at follow up. In the present study, an mRS score of 5-6 was considered as a grave outcome. 


\section{Clinical and imaging data}

Patient demographics, vascular risk factors, stroke etiology and laboratory results, and critical pathway data were retrieved from our Acute Ischemic Stroke and Thrombolysis databases. We further evaluated the first NECT scan and CT angiography obtained for each patient using the Alberta Stroke Program Early CT (ASPECTS) and IAC scores, respectively. The ASPECTS was determined from the initial NECT; scores $\geq 8$ were considered high and those $<8$ were considered low. ${ }^{24}$ IAC scores were determined from CT angiography MIP images using a previously described method in which the number of intracranial calcified arteries was counted. ${ }^{1}$ Calcification was defined as the presence of hyperdense foci along the artery with a peak intensity $>130$ Hounsfield units $(\mathrm{HU})$ with adjustments of window setting to differentiate contrast. ${ }^{1,25}$ This semi-quantitative scoring system was applied to 7 intracranial arteries: the right and left internal carotid starting from the cavernous segment to the communicating segment, the right and left middle cerebral, the right and left vertebral, and the basilar arteries. The IAC score was the number of arteries showing calcification, and therefore ranged from 0 (no calcification) to 7 (calcification in all 7 intracranial arteries examined). Patients were assigned to 1 of 2 groups depending on their IAC score. Patients with low IAC scores $(<3)$ were assigned to the low calcification burden (LCB) group, whereas patients with high IAC scores $(\geq 3)$ were assigned to the high calcification burden (HCB) group (Figure 1). From our preliminary receiver operating characteristic curve analysis, dichotomizing 0-2 and 3-7 had the largest area under the receiver operating characteristic curve among various combinations for grave outcome. On this ground, patients with low IAC scores $(<3)$ were assigned to the low calcification burden (LCB) group, whereas patients with high IAC scores $(\geq 3)$ were assigned to the high calcification burden ( $\mathrm{HCB})$ group (Figure 1). Before IA treatment began, leptomeningeal collaterals from the ipsilateral anterior cerebral artery were evaluated and graded with transfemoral cerebral angiography, as previously reported. ${ }^{26}$ This collateral grade was not evaluated when the MCA was fully or partially recanalized. Following either IV or IA treatment, final reperfusion status was evaluated using the thrombolysis in cerebral infarction (TICI) system. ${ }^{26} \mathrm{~A}$ TICI score of $2 \mathrm{~b}-3$ (reperfusion in $\geq 67 \%$ ) was considered to indicate a good reperfusion, whereas lower TICI scores indicated a poor reperfusion. ${ }^{27}$ Post-treatment intracerebral hemorrhages were evaluated according to criteria defined by the European Cooperative Acute Stroke Study. ${ }^{28}$ The final infarct volume was determined using the total volume of diffusion restriction lesions observed on MRIs obtained between 1 and 7 days following revascularization treatment. When MRI was unavailable, the final infarct volume was determined from the total hypodensity observed on CTs obtained during the same time period. The infarct volume was calculated using a previously described semi-quantitative method. ${ }^{29}$ Calcification scoring and other imaging analyses were performed with consensus by raters who were blinded to the clinical information (S. J. Lee, J. W. Choi, J. S. Lee).

\section{Statistical analysis}

Differences between the LCB and HCB groups were analyzed
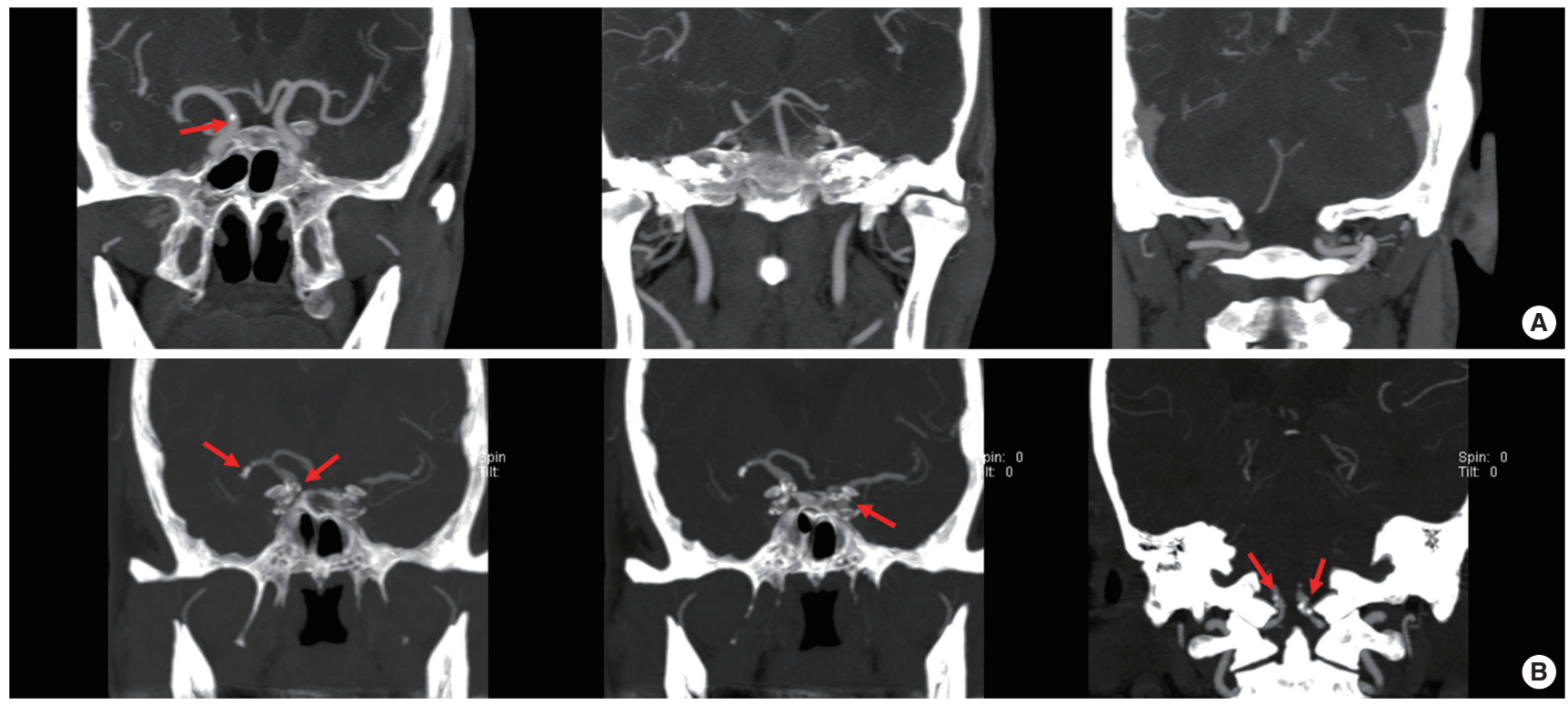

Figure 1. Representative patient categorization based on the number of intracranial arterial calcifications. One calcification is shown in the terminal segment of the right internal carotid artery. This case was assigned to the low calcification burden group. Five calcifications are shown in the right middle cerebral artery, the right and left terminal internal carotid, and the distal vertebral arteries. This case was assigned to the high calcification burden group. 
Table 1. Baseline characteristics

\begin{tabular}{|c|c|c|c|}
\hline & $\operatorname{LCB}(n=65)$ & $\mathrm{HCB}(n=15)$ & $P$ value \\
\hline Age & $61.63 \pm 13.91$ & $72.47 \pm 9.69$ & 0.006 \\
\hline Male gender & $38 / 65(58.5 \%)$ & $6 / 15(40.0 \%)$ & 0.195 \\
\hline Hypertension & $36 / 56(64.3 \%)$ & $10 / 14(71.4 \%)$ & 0.615 \\
\hline Diabetes mellitus & 7/56 (12.5\%) & 6/14 (42.9\%) & 0.009 \\
\hline NIHSS score on admission & $14.58 \pm 3.84$ & $13.27 \pm 2.71$ & 0.215 \\
\hline Total cholesterol (mg/dL) & $165.6 \pm 42.72$ & $158.64 \pm 33.33$ & 0.574 \\
\hline Glucose (mg/dL) & $131.23 \pm 31.84$ & $190 \pm 102.62$ & 0.053 \\
\hline Homocysteine (mg/dL) & $11.03 \pm 3.69$ & $13.98 \pm 4.91$ & 0.032 \\
\hline Atrial fibrillation & $39(61.9 \%)$ & $4(26.7 \%)$ & 0.014 \\
\hline TOAST classification & & & $<0.001$ \\
\hline Large artery atherosclerosis & $14(21.5 \%)$ & $6(40.0 \%)$ & \\
\hline Cardioembolism & $45(69.2 \%)$ & $3(20.0 \%)$ & \\
\hline Undetermined, 2 etiologies & $1(1.5 \%)$ & $3(20.0 \%)$ & \\
\hline Lacunar infarct & $0(0.0 \%)$ & $0(0.0 \%)$ & \\
\hline Other determined & $2(3.1 \%)$ & $0(0.0 \%)$ & \\
\hline Undetermined incomplete evaluation & $3(4.6 \%)$ & $3(20.0 \%)$ & \\
\hline Dense MCA sign & $43(66.2 \%)$ & $7(50 \%)$ & 0.255 \\
\hline ASPECTS score $\geq 8$ & 23/63 (36.5\%) & $7 / 13(53.8 \%)$ & 0.244 \\
\hline Stenosis of relevant proximal artery & $3(4.6 \%)$ & $0(0 \%)$ & 0.396 \\
\hline Stenosis of irrelevant artery & $9(13.8 \%)$ & $5(33.3 \%)$ & 0.073 \\
\hline Leptomeningeal collateral grading by DSA & $\mathrm{n}=41$ & $\mathrm{n}=11$ & 0.386 \\
\hline 0, none & $3(7.3 \%)$ & $1(9.1 \%)$ & \\
\hline 1, partial and slow & $17(41.5 \%)$ & $1(9.1 \%)$ & \\
\hline 2. partial and rapid & $8(19.5 \%)$ & $3(27.3 \%)$ & \\
\hline 3 , full and slow & $11(26.8 \%)$ & $5(45.5 \%)$ & \\
\hline 4 , full and rapid & $2(4.9 \%)$ & $1(9.1 \%)$ & \\
\hline
\end{tabular}

LCB, low calcification burden; HCB, high calcification burden; NIHSS, National Institutes of Health Stroke Scale; MCA, middle cerebral artery; ASPECTS, Alberta Stroke Program Early Computed Tomography; DSA, digital subtraction angiography; TOAST, Trial of Org 10172 in Acute Stroke Treatment.

using a $\chi^{2}$ test for categorical variables and Student's $t$-test for continuous variables. Multiple logistic regression analysis was performed to verify the significance of IAC burden as a risk factor for grave outcomes. A $P$ value of $<0.05$ was considered statistically significant. All statistical analyses were performed with statistical software IBM SPSS Statistics 19 (Chicago, IL, USA).

\section{Results}

\section{Demographic and clinical characteristics}

The baseline characteristics of patients in both groups are presented in Table 1. Of the 80 patients studied, 65 were assigned to the LCB group and 15 were assigned to the HCB group. Patients in the HCB group were significantly older $(72.5 \pm 9.7$ years vs. $61.6 \pm 13.9$ years, $P=0.006$ ), and were more likely to have diabetes ( $42.9 \%$ vs. $12.5 \%, P=0.009$ ) than those in the LCB group. Serum homocysteine levels also were significantly higher in the $\mathrm{HCB}$ group $(14.0 \pm 4.9 \mu \mathrm{mol} / \mathrm{L}$ vs. $11.0 \pm 3.7 \mu \mathrm{mol} / \mathrm{L}, P=0.032)$ than in the LCB group. The HCB group included a higher proportion of large artery atherosclerosis, whereas the LCB group included a higher proportion of cardioembolic stroke $(P<0.001)$.

Our analysis of the initial $\mathrm{CT}$ and transfemoral cerebral angi-
Table 2. A multiple logistic regression model for predicting high intracranial arterial calcification score (3 or higher)

\begin{tabular}{lcc}
\hline & Odds ratio (95\% CI) & $P$ value \\
\hline Age & $1.108(1.025-1.197)$ & 0.010 \\
Male gender & $1.080(0.245-4.758)$ & 0.919 \\
Initial NIHSS & $0.896(0.750-1.071)$ & 0.228 \\
Diabetes mellitus & $7.114(1.457-35.038)$ & 0.015
\end{tabular}

Cl, confidence interval; NIHSS, National Institutes of Health Stroke Scale.

ographic findings failed to reveal significant differences between groups in the number of patients showing a dense MCA sign, ASPECTS scores $\geq 8$, or the extent of leptomeningeal collaterals from the ipsilateral anterior cerebral artery.

A multiple regression model showed that both age and presence of diabetes mellitus were independent predictors for high IAC score (Table 2).

\section{Therapeutic regimens and imaging outcomes}

There were no differences in treatment regimens or imaging outcomes between the 2 groups (Table 3). IV rtPA was infused in 12 (80\%) patients in the HCB group, and 46 (70.8\%) patients in the LCB group $(P=0.470)$. The IA recanalization procedure was 
Table 3. Radiologic and post-treatment clinical outcomes

\begin{tabular}{|c|c|c|c|}
\hline & $\operatorname{LCB}(n=65)$ & $\mathrm{HCB}(n=15)$ & $P$ value \\
\hline IV rtPA infused & $46(70.8 \%)$ & $12(80 \%)$ & 0.470 \\
\hline IA intervention & $55(84.6 \%)$ & $12(80 \%)$ & 0.662 \\
\hline Fibrinolytic infusion & $29(52.7 \%)$ & $7(58.3 \%)$ & 0.724 \\
\hline Angioplasty & $9(16.4 \%)$ & $1(8.3 \%)$ & 0.479 \\
\hline Intracranial stenting & $2(3.6 \%)$ & $0(0 \%)$ & 0.502 \\
\hline Mechanical thrombectomy & $23(41.8 \%)$ & $5(41.7 \%)$ & 0.992 \\
\hline Final good reperfusion grades & $45(69.2 \%)$ & $10(66.7 \%)$ & 0.847 \\
\hline \multicolumn{4}{|l|}{ Procedure time (min) } \\
\hline Onset to tPA & $122 \pm 42$ & $119 \pm 33$ & 0.257 \\
\hline Onset to puncture & $240 \pm 67$ & $216 \pm 52$ & 0.295 \\
\hline Puncture to working projection & $33 \pm 54$ & $26 \pm 13$ & 0.691 \\
\hline Procedure duration & $78 \pm 50$ & $62 \pm 42$ & 0.331 \\
\hline Postprocedure intracerebral hemorrahge & $(n=64)$ & $(n=14)$ & 0.923 \\
\hline Hemorrhagic infarct type 1 & $11(17.2 \%)$ & $2(14.3 \%)$ & \\
\hline Hemorrhagic infarct type 2 & $16(25.0 \%)$ & $4(28.6 \%)$ & \\
\hline Parenchymal hemorrhage type 1 & $9(14.1 \%)$ & $1(7.1 \%)$ & \\
\hline Parenchymal hemorrhage type 2 & $9(14.1 \%)$ & $3(21.4 \%)$ & \\
\hline Postprocedure subarachnoid hemorrhage & $2(3.1 \%)$ & $3(21.4 \%)$ & 0.011 \\
\hline Final infarct volume $\left(\mathrm{mm}^{3}\right)$ & $120.76 \pm 128.99$ & $144.06 \pm 115.6$ & 0.523 \\
\hline Improvement in NIHSS $\geq 4$ while admitted & $45(78.9 \%)$ & $6(42.9 \%)$ & 0.007 \\
\hline Deterioration in NIHSS $\geq 4$ while admitted & $4(6.5 \%)$ & $6(40.0 \%)$ & 0.001 \\
\hline NIHSS at discharge & $7.87 \pm 8.28$ & $16.00 \pm 12.28$ & 0.003 \\
\hline Functional status at 3 months & $(n=59)$ & $(n=14)$ & \\
\hline Good (mRS 0-2) & $31(52.5 \%)$ & $3(21.4 \%)$ & 0.036 \\
\hline Grave (mRS 5-6) & $13(22 \%)$ & $8(57.1 \%)$ & 0.009 \\
\hline Mortality & $10(16.9 \%)$ & $6(42.9 \%)$ & 0.035 \\
\hline
\end{tabular}

LCB, low calcification burden; HCB, high calcification burden; rtPA, recombinant tissue plasminogen activator; IA, intra-arterial; NIHSS, National Institutes of Health Stroke Scale; mRS, modified Rankin Scale.

performed in $12(80.0 \%)$ patients in the HCB group and in 55 (84.6\%) patients in the LCB group $(P=0.255)$. There was no significant difference in the frequency of each IA method. IV tPA infusion time or procedure times did not differ between groups. The final angiographic outcome, as assessed by the proportion of patients with good reperfusion, did not differ between groups. The final infarct volumes (HCB: $144.1 \pm 115.6 \mathrm{~mL}$ vs. LCB: $120.8 \pm 129.0 \mathrm{~mL}, P=0.523)$ did not differ between groups.

\section{Poor outcomes}

Finally, the HCB group showed poorer outcomes compared to the LCB group (Table 3). The NIHSS score at discharge was significantly higher in the HCB group than in the LCB group $(16.0 \pm 12.3$ vs. $7.9 \pm 8.3, P=0.003)$. Patients in the $\mathrm{HCB}$ group more frequently showed deterioration ( $>3$ point increases) in NIHSS scores than patients in the LCB group ( $40.0 \%$ vs. $6.5 \%$, $P=0.001)$. Moreover, a grave outcome (mRS 5-6) at 3 months after stroke onset was more common in the HCB group than in the LCB group ( $57.1 \%$ vs. $22.0 \%, P=0.009$ ). The causes of death were similar between the groups (Table 4). In a multiple logistic regression model, $\mathrm{HCB}$ was an independent predictor
Table 4. Causes of death within 3 months of middle cerebral artery trunk occlusion

\begin{tabular}{lcc}
\hline & LCB & HCB \\
\hline Mortality & $10 / 65$ & $6 / 15$ \\
Malignant stroke & 6 & 3 \\
Cardiac event & 2 & 2 \\
Sepsis & 2 & 0 \\
Unknown & 0 & 1 \\
\hline
\end{tabular}

LCB, low calcification burden; HCB, high calcification burden; mRS, modified Rankin Scale.

for a poor outcome at 3 months after adjusting for age, sex, initial NIHSS score, and the reperfusion grade (odds ratio 4.135, 95\% confidence interval, 1.045-16.359, $P=0.043$; Table 5). When presence of diabetes mellitus and atrial fibrillation were incorporated into those confounding factors, HCB was not an independent predictor. Diabetes mellitus appeared to be stronger predictor for clinical outcome.

\section{Discussion}

In the present study, we demonstrate that IAC significantly 
Table 5. Multiple logistic regression model for predicting grave outcomes at 3 months, in patients with acute MCA trunk occlusion and recanalization treatments

\begin{tabular}{|c|c|c|c|c|}
\hline & & & & \\
\hline & Odds ratio (95\% Cl) & $P$ value & Odds ratio (95\% Cl) & $P$ value \\
\hline Age & $1.076(1.016-1.139)$ & 0.012 & $1.089(1.015-1.167)$ & 0.017 \\
\hline Male gender & $0.707(0.200-2.494)$ & 0.589 & $0.904(0.224-3.648)$ & 0.887 \\
\hline Initial NIHSS & $1.088(0.910-1.302)$ & 0.355 & $1.175(0.947-1.459)$ & 0.143 \\
\hline Good reperfusion (TICI 2b-3) & $0.911(0.266-3.116)$ & 0.882 & $1.069(0.263-4.342)$ & 0.926 \\
\hline High calcification burden & $4.135(1.045-16.359)$ & 0.043 & $1.357(0.248-7.414)$ & 0.725 \\
\hline Diabetes mellitus & - & - & $7.194(1.257-41.194)$ & 0.027 \\
\hline Atrial fibrillation & - & - & $0.611(0.123-3.035)$ & 0.547 \\
\hline
\end{tabular}

Cl, confidence interval; NIHSS, National Institutes of Health Stroke Scale; TICl, thrombolysis in cerebral infarction.

influences poor outcomes in a homogenous population of patients with acute ischemic stroke. Specifically, patients with MCA trunk occlusion who underwent revascularization therapy and with an HCB in their intracranial arteries rarely showed neurological improvement. In general, cardioembolic stroke results in greater disability than does atherosclerotic stroke. In the present study, however, the LCB group, which consisted mostly of cardioembolism, showed less disability than the HCB group, which consisted mostly of atherosclerosis.

A poorer disability in patients with $\mathrm{HCB}$ was attributed to neurological deterioration following revascularization treatments. One may presume that intracranial HCB is associated with coronary artery disease, and that cardiac disease may influence mortality and morbidity following stroke. However, there was no difference in cardiac events between groups when mortality occurred within 3 months. Most HCB patients that demonstrated grave outcome, which was defined as being bed-ridden or deceased, often showed deterioration and little improvement in their neurological status (NIHSS scores). A previous study of acute ischemic stroke patients who underwent revascularization therapy revealed that approximately $60 \%$ of the patients showed neurological improvement, whereas the remaining $40 \%$ showed no improvement. $^{22}$ As for our patients, approximately $80 \%$ of the LCB patients showed improvement in their neurological status during their hospital admission. This outcome can be considered good when compared to those described in the previous report. ${ }^{22}$ In our study, however, the majority of patients with HCB showed no neurological recovery and often showed further deterioration.

Even though the post-treatment reperfusion grade was as high as $70 \%$, which immediate revascularization usually predicts a good outcome, ${ }^{30} \mathrm{HCB}$ patients generally showed poor neurological recovery. This poor neurological recovery could be explained by vascular aging, a phenomenon associated with arterial calcification. In addition to chronological aging ${ }^{31}$ and accumulation of advanced glycation end products, ${ }^{32}$ calcium deposition is a primary component of vascular aging, which is characterized by en- dothelial dysfunction. ${ }^{32}$ A number of previous reports support such an interpretation. Firstly, vascular aging may be associated with post-ischemic expansion of the infarction due to poor recovery from the ischemia-reperfusion injury. ${ }^{33}$ Secondly, chronically high levels of reactive oxygen species accompanying the vascular calcification process can hamper neovascularization after reperfusion. ${ }^{34}$ High levels of reactive oxygen species significantly impair endothelial progenitor cell function, which further increases reactive oxygen species levels. Many diseases such as diabetes type I and II are associated with a decrease in both the function and number of endothelial progenitor cells. ${ }^{35}$ Endothelial progenitor cells are essential to neovascularization in poststroke repair; therefore, any disturbance in their activity could impair neurological recovery. ${ }^{36,37}$

Intracranial $\mathrm{HCB}$ can be an imaging marker for predicting a poorer prognosis. In the present study, the therapeutic regimens and radiological outcomes did not differ between the HCB and LCB groups. However, some well-known vascular factors associated with arterial calcification differed between the groups, such as age, co-morbidity with diabetes mellitus, and initial serum levels of glucose and homocysteine. ${ }^{38-40}$ Among these factors, an older age and diabetes mellitus are regarded as prognostic factors for a poorer outcome, and European guidelines limit intravenous rtPA infusion in acute stroke patients who are over 80 years of age, or who have diabetes with a history of stroke. ${ }^{41,42}$ Nevertheless, available data for factors such as an older age and the presence of diabetes mellitus are inconclusive. ${ }^{27,43-46}$ Our results show that intracranial HCB was associated with both age and diabetes and is more likely to indicate a poor outcome because this measure appears to reflect such major risk factors, none of which, however, can directly predict the clinical outcome. IAC burden can be easily measured even with $\mathrm{NECT},{ }^{47}$ which is typically performed prior to thrombolytic treatment. Further studies that include large clinical trials for stroke thrombolytic treatment should prove useful in confirming intracranial HCB as a prognostic marker. 
There are several limitations to our study. Firstly, instead of using a quantitative calcification burden score that was used previously to assess coronary atherosclerosis, we used a semi-quantitative scoring system. We chose this method of analysis because quantitative analysis of IAC burden is not easily performed due to the close proximity of bony structures. Secondly, this study examined patients with acute MCA trunk occlusion, and therefore might not reflect the calcification burdens for patients treated with revascularization therapy for other vascular structures. Our strict occlusion site criterion was selected to allow a homogenous assessment of collateral grading that primarily measures the ipsilateral anterior cerebral artery leptomeningeal collaterals, which cannot be readily applied to distal internal carotid or basilar artery occlusions. Further studies are required to validate the significance of calcification burdens on outcomes with other vascular beds.

\section{Conclusions}

Intracranial HCB was associated with a grave prognosis after revascularization treatment for hyperacute ischemic stroke. In our analysis, we focused on patients who had an MCA trunk occlusion. Thus, further studies examining other forms of intracranial arterial occlusion are required to establish $\mathrm{HCB}$ as a reliable marker.

\section{References}

1. Bugnicourt JM, Leclercq C, Chillon JM, Diouf M, Deramond $\mathrm{H}$, Canaple S, et al. Presence of intracranial artery calcification is associated with mortality and vascular events in patients with ischemic stroke after hospital discharge: a cohort study. Stroke 2011;42:3447-3453.

2. Kassab MY, Gupta R, Majid A, Farooq MU, Giles BP, Johnson $\mathrm{MD}$, et al. Extent of intra-arterial calcification on head CT is predictive of the degree of intracranial atherosclerosis on digital subtraction angiography. Cerebrovasc Dis 2009;28:45-48.

3. Oliver MF. The diagnostic value of detecting coronary calcification. Circulation 1970;42:981-982.

4. Rennenberg RJ, Kessels AG, Schurgers LJ, van Engelshoven JM, de Leeuw PW, Kroon AA. Vascular calcifications as a marker of increased cardiovascular risk: a meta-analysis. Vasc Health Risk Manag 2009;5:185-197.

5. Koton S, Tashlykov V, Schwammenthal Y, Molshatzki N, Merzeliak $\mathrm{O}$, Tsabari $\mathrm{R}$, et al. Cerebral artery calcification in patients with acute cerebrovascular diseases: determinants and long-term clinical outcome. Eur J Neurol 2012;19:739-745.

6. Wayhs R, Zelinger A, Raggi P. High coronary artery calcium scores pose an extremely elevated risk for hard events. J Am Coll Cardiol 2002;39:225-230.

7. Lansky AJ, Goto K, Cristea E, Fahy M, Parise H, Feit F, et al. Clinical and angiographic predictors of short- and long-term ischemic events in acute coronary syndromes: results from the Acute Catheterization and Urgent Intervention Triage strategY (ACUITY) trial. Circ Cardiovasc Interv 2010;3:308-316.

8. Honda Y, Toyama T, Miyaishi Y, Kan H, Kawaguchi R, Adachi $\mathrm{H}$, et al. Coronary artery calcification as a new predictor of nontarget lesion revascularization during the chronic phase after successful percutaneous coronary intervention. Cardiovasc Interv Ther 2014;29:315-323.

9. Wang FF, Han JL, He R, Zeng XZ, Zhang FC, Guo LJ, et al. Prognostic value of coronary artery calcium score in patients with stable angina pectoris after percutaneous coronary intervention. J Geriatr Cardiol 2014;11:113-119.

10. Molina CA, Alvarez-Sabin J. Recanalization and reperfusion therapies for acute ischemic stroke. Cerebrovasc Dis 2009;27 Suppl 1:162-167.

11. The National Institute of Neurological Disorders and Stroke rtPA Stroke Study Group. Tissue plasminogen activator for acute ischemic stroke. N Engl J Med 1995;333:1581-1587.

12. Ueda T, Hatakeyama T, Kohno K, Kumon Y, Sakaki S. Endovascular treatment for acute thrombotic occlusion of the middle cerebral artery: local intra-arterial thrombolysis combined with percutaneous transluminal angioplasty. Neuroradiology 1997;39:99-104.

13. Kim DJ, Kim DI, Kim SH, Lee KY, Heo JH, Han SW. Rescue localized intra-arterial thrombolysis for hyperacute MCA ischemic stroke patients after early non-responsive intravenous tissue plasminogen activator therapy. Neuroradiology 2005;47: 616-621.

14. IMS II Trial Investigators. The Interventional Management of Stroke (IMS) II Study. Stroke 2007;38:2127-2135.

15. Smith WS, Sung G, Saver J, Budzik R, Duckwiler G, Liebeskind DS, et al. Mechanical thrombectomy for acute ischemic stroke: final results of the Multi MERCI trial. Stroke 2008;39:1205-1212.

16. Penumbra Pivotal Stroke Trial Investigators. The penumbra pivotal stroke trial: safety and effectiveness of a new generation of mechanical devices for clot removal in intracranial large vessel occlusive disease. Stroke 2009; 40:2761-2768.

17. Nogueira RG, Yoo AJ, Buonanno FS, Hirsch JA. Endovascular approaches to acute stroke, part 2: a comprehensive review of studies and trials. AJNR Am J Neuroradiol 2009;30:859-875.

18. Castano C, Dorado L, Guerrero C, Millan M, Gomis M, Perez de la Ossa N, et al. Mechanical thrombectomy with the Solitaire $\mathrm{AB}$ device in large artery occlusions of the anterior circulation: a pilot study. Stroke 2010;41:1836-1840. 
19. Roth C, Papanagiotou P, Behnke S, Walter S, Haass A, Becker C, et al. Stent-assisted mechanical recanalization for treatment of acute intracerebral artery occlusions. Stroke 2010;41:2559-2567.

20. Saver JL, Jahan R, Levy EI, Jovin TG, Baxter B, Nogueira RG, et al. Solitaire flow restoration device versus the Merci Retriever in patients with acute ischaemic stroke (SWIFT): a randomised, parallel-group, non-inferiority trial. Lancet 2012;380:1241-1249.

21. Rha JH, Saver JL. The impact of recanalization on ischemic stroke outcome: a meta-analysis. Stroke 2007;38:967-973.

22. Bang OY, Liebeskind DS, Saver JL, Kim GM, Chung CS, Lee KH. Stunned brain syndrome: serial diffusion perfusion MRI of delayed recovery following revascularisation for acute ischaemic stroke. J Neurol Neurosurg Psychiatry 2011;82:27-32.

23. Suh HI, Lee SW, Eom YI, Lee JS. A Case of Delayed Neurological Recovery with Luxury Perfusion and a High Intracranial Arterial Calcification Burden. Journal of Stroke 2014;16:51-53.

24. Barber PA, Demchuk AM, Zhang J, Buchan AM. Validity and reliability of a quantitative computed tomography score in predicting outcome of hyperacute stroke before thrombolytic therapy. ASPECTS Study Group. Alberta Stroke Programme Early CT Score. Lancet 2000;355:1670-1674.

25. Saba L, Mallarin G. Window settings for the study of calcified carotid plaques with multidetector CT angiography. AJNR Am J Neuroradiol 2009;30:1445-1450.

26. Higashida RT, Furlan AJ, Roberts H, Tomsick T, Connors B, Barr J, et al. Trial design and reporting standards for intra-arterial cerebral thrombolysis for acute ischemic stroke. Stroke 2003; 34:e109-137.

27. Tomsick T, Broderick J, Carrozella J, Khatri P, Hill M, Palesch Y, et al. Revascularization results in the Interventional Management of Stroke II trial. AJNR Am J Neuroradiol 2008;29:582-587.

28. Fiorelli M, Bastianello S, von Kummer R, del Zoppo GJ, Larrue V, Lesaffre E, et al. Hemorrhagic transformation within 36 hours of a cerebral infarct: relationships with early clinical deterioration and 3-month outcome in the European Cooperative Acute Stroke Study I (ECASS I) cohort. Stroke 1999;30:2280-2284.

29. Oppenheim C, Samson Y, Manai R, Lalam T, Vandamme X, Crozier $\mathrm{S}$, et al. Prediction of malignant middle cerebral artery infarction by diffusion-weighted imaging. Stroke 2000;31: 2175-2181.

30. Humpich M, Singer OC, du Mesnil de Rochemont R, Foerch C, Lanfermann H, Neumann-Haefelin T. Effect of early and delayed recanalization on infarct pattern in proximal middle cerebral artery occlusion. Cerebrovasc Dis 2006;22:51-56.

31. Chen XY, Lam WW, Ng HK, Fan YH, Wong KS. The frequency and determinants of calcification in intracranial arteries in Chinese patients who underwent computed tomography examinations. Cerebrovasc Dis 2006;21:91-97.
32. Lee HY, Oh BH. Aging and arterial stiffness. Circ J 2010;74: 2257-2262.

33. Palomares SM, Cipolla MJ. Vascular Protection Following Cerebral Ischemia and Reperfusion. J Neurol Neurophysiol 2011; 2011.

34. Serrano CV, Jr., Oranges M, Brunaldi V, de MSA, Torres TA, Nicolau JC, et al. Skeletonized coronary arteries: pathophysiological and clinical aspects of vascular calcification. Vasc Health Risk Manag 2011;7:143-151.

35. Fleissner F, Thum T. Critical role of the nitric oxide/reactive oxygen species balance in endothelial progenitor dysfunction. Antioxid Redox Signal 2011;15:933-948.

36. Asahara T, Murohara T, Sullivan A, Silver M, van der Zee R, Li $\mathrm{T}$, et al. Isolation of putative progenitor endothelial cells for angiogenesis. Science 1997;275:964-967.

37. Font MA, Arboix A, Krupinski J. Angiogenesis, neurogenesis and neuroplasticity in ischemic stroke. Curr Cardiol Rev 2010; $6: 238-244$

38. Newman AB, Naydeck BL, Sutton-Tyrrell K, Feldman A, Edmundowicz D, Kuller LH. Coronary artery calcification in older adults to age 99: prevalence and risk factors. Circulation 2001;104:2679-2684.

39. Schurgin S, Rich S, Mazzone T. Increased prevalence of significant coronary artery calcification in patients with diabetes. $\mathrm{Di}$ abetes Care 2001;24:335-338.

40. Kullo IJ, Li G, Bielak LF, Bailey KR, Sheedy PF, 2nd, Peyser PA, et al. Association of plasma homocysteine with coronary artery calcification in different categories of coronary heart disease risk. Mayo Clin Proc 2006;81:177-182.

41. Johnston KC, Connors AF, Jr., Wagner DP, Knaus WA, Wang $\mathrm{X}$, Haley EC, Jr. A predictive risk model for outcomes of ischemic stroke. Stroke 2000;31:448-455.

42. Hacke W, Kaste M, Bluhmki E, Brozman M, Davalos A, Guidetti $\mathrm{D}$, et al. Thrombolysis with alteplase 3 to 4.5 hours after acute ischemic stroke. N Engl J Med 2008;359:1317-1329.

43. Mateen FJ, Buchan AM, Hill MD. Outcomes of thrombolysis for acute ischemic stroke in octogenarians versus nonagenarians. Stroke 2010;41:1833-1835.

44. Bhatnagar P, Sinha D, Parker RA, Guyler P, O’Brien A. Intravenous thrombolysis in acute ischaemic stroke: a systematic review and meta-analysis to aid decision making in patients over 80 years of age. J Neurol Neurosurg Psychiatry 2011;82:712-717.

45. Mishra NK, Diener HC, Lyden PD, Bluhmki E, Lees KR. Influence of age on outcome from thrombolysis in acute stroke: a controlled comparison in patients from the Virtual International Stroke Trials Archive (VISTA). Stroke 2010;41:2840-2848.

46. Mono ML, Romagna L, Jung S, Arnold M, Galimanis A, Fischer $\mathrm{U}$, et al. Intra-arterial thrombolysis for acute ischemic stroke 
in octogenarians. Cerebrovasc Dis 2012;33:116-122.

47. Bugnicourt JM, Chillon JM, Massy ZA, Canaple S, Lamy C, Deramond $\mathrm{H}$, et al. High prevalence of intracranial artery calci- fication in stroke patients with CKD: a retrospective study. Clin J Am Soc Nephrol 2009;4:284-290. 